\title{
Can methyl jasmonate treatment of conifer seedlings be used as a tool to stop height growth in nursery forest trees?
}

\author{
Frauke Fedderwitz ${ }^{1,4}$ (D) Niklas Björklund ${ }^{1} \cdot$ Ronny Anngren ${ }^{2,5} \cdot$ Anders Lindström $^{3}$. \\ Göran Nordlander ${ }^{1}$
}

Received: 11 February 2019 / Accepted: 30 July 2019 / Published online: 12 August 2019

(c) The Author(s) 2019

\begin{abstract}
A plant's induced defense system can be triggered by the application of the plant hormone methyl jasmonate (MeJA), and recent research suggest that MeJA treatment may become a tool for protection of conifer seedlings against insect herbivory (e.g. by the pine weevil Hylobius abietis). A side-effect of MeJA application is temporarily reduced height growth. This has generally been considered as negative, but in forest tree nurseries this could instead be beneficial since it is commonly desired to stop the growth of nursery seedlings in late summer. Artificially longer dark periods (long nights/short days) are widely used in high-latitude nurseries to terminate height growth and induce freezing tolerance. However, long night treatment requires specialized nursery equipment and are labor intensive. Therefore alternatives are sought after. We compared long-night and MeJA treatments by following the growth of Norway spruce (Picea abies) seedlings throughout one season. The regulatory effect of MeJA on height growth was similar if not even better than that of long nights, i.e. it was terminated faster. However, MeJA treatment also reduced root growth and delayed the development of freezing tolerance. MeJA may therefore not replace long-night treatments, but it could facilitate a more flexible application of long nights by gaining a longer time interval during which this treatment can be used without risking the seedlings growing too large.
\end{abstract}

Keywords Diameter · Forest regeneration · Freezing tolerance $\cdot$ Long night treatment · Picea abies $\cdot$ Root growth $\cdot$ Short day treatment

Electronic supplementary material The online version of this article (https://doi.org/10.1007/s1105 6-019-09737-6) contains supplementary material, which is available to authorized users.

Frauke Fedderwitz

frauke.fedderwitz@slu.se

1 Department of Ecology, Swedish University of Agricultural Sciences (SLU), Box 7044, 75007 Uppsala, Sweden

2 Nässja Tree Nursery, Bergvik Skog Plantor AB, Berreksvägen 45, 81020 Österfärnebo, Sweden

3 School of Industrial Technology and Business Studies, Dalarna University, 79188 Falun, Sweden

4 Present Address: Crop Research Centre, Teagasc, Oak Park, Ireland

5 Present Address: Rural Economy and Agricultural Society Halland, Lilla Böslid 146, 30596 Eldsberga, Sweden 


\section{Introduction}

Methyl jasmonate (MeJA) is a naturally occurring plant hormone that activates the plant's induced defense system (Jiang and Yan 2018; Yu et al. 2018). Most research on MeJA has focused on agricultural crops and fruits (Yu et al. 2018), but MeJA has also been evaluated as a successful plant protection treatment in several forest-pest insect systems (e.g. Gu et al. 2018; Jiang and Yan 2018; Zhao et al. 2011). Further, in recent years treatment with methyl jasmonate (MeJA) has become a promising tool for protecting conifer seedlings against the pine weevil, Hylobius abietis (L.) (e.g. Berglund et al. 2016; Fedderwitz et al. 2016; López-Goldar et al. 2018; Lundborg et al. 2016a; Lundborg et al. 2016b; Zas et al. 2014). By applying MeJA, or another elicitor, before the seedlings are exposed to herbivores, they are better protected and experience lower damage rates without being physically damaged by the treatment (Jiang and Yan 2018). However, the allocation of recourses to induced defenses has other consequences for the plants. For example, Scots pine seedlings treated with high concentrations of MeJA had, besides an increased number of resin ducts, also a reduced tracheid cell lumen area and net photosynthesis rate (Heijari et al. 2005). Several previously published studies have noted temporarily reduced height growth of conifer seedlings after MeJA treatments (e.g. Gould et al. 2009; Heijari et al. 2005; Moreira et al. 2012; Sampedro et al. 2011; Vivas et al. 2012; Zas et al. 2014).

A treatment that reduces height growth might not seem an ideal solution for seedling production. However, during the production of conifer seedlings, forest tree nurseries in Scandinavia and northern North America regularly use long night (LN) treatments (also termed short day treatments) to promote early growth cessation and induce bud set (e.g. Colombo et al. 2001; Fløistad and Granhus 2013; Jacobs et al. 2008; Kohmann and Johnsen 2007; Wallin et al. 2017). This is done by covering the seedlings with black curtains, creating an artificial LN for 12-16 h (Colombo et al. 2001; Wallin et al. 2017). Besides termination of growth and bud set, this treatment initiates the processes of dormancy induction and freezing tolerance. The main aims of using LN treatments in nurseries are to increase the robustness of seedlings for handling by stopping apical growth, promoting bud set, and to induce an earlier freezing tolerance (Colombo et al. 2001; Kohmann and Johnsen 2007; Wallin et al. 2017) for safer autumn planting or frozen storage. Autumn planting of seedlings can nowadays occur quite late in the season, i.e. until the soil is frozen or covered by snow (Luoranen et al. 2018). Thus resistance to handling and freezing tolerance is important for both autumn-planted seedlings and those that are to be stored frozen until they are planted next spring. The problem with using LN on a large scale, however, is the high cost of building and maintaining specialized plant beds. Many nurseries therefore only have a few such beds available, and have to rotate plants between LN and non-LN beds. This makes it difficult to use LN-treatments for just terminating the growth since the growth frequently needs to be terminated for large quantities of seedling within a short time frame. There is therefore an urge for a convenient method to terminate the growth of large quantities of seedlings at the same time.

Here MeJA treatment could offer an interesting solution. As described above, MeJA treatment provides enhanced defense against insects and additionally reduces height growth of seedlings, both target properties for forest tree nurseries. To be able to exploit MeJA as a treatment in forest nurseries, the reactions of the plants should be fast, perceptible and uniform. Hence the main aim of this study was to compare the growth development of MeJA-treated Norway spruce (Picea abies (L.) Karst) seedlings with both untreated and LN-treated seedlings. We evaluated the influence of different concentrations of MeJA on 
seedling growth during late summer/autumn as well as how MeJA treatment affects the development of freezing tolerance. This is the first study to look specifically at height growth reduction after MeJA treatments as an advantage, rather than as a disadvantage.

\section{Materials and methods}

\section{Seedling material}

Two Norway spruce batches based on seeds collected in the orchard of Almnäs, $40 \mathrm{~km}$ southwest of Stockholm, Sweden, where the seed origin was latitude $59^{\circ} 00^{\prime} \mathrm{N}$, were used in this study. The seeds were sown in $50 \mathrm{ml}$ container cavities filled with peat in containers, with 121 cavities at a density of 820 cavities $/ \mathrm{m}^{2}$ (Plantek121, Lännen OY, Säkylä, Finland) in July 2015 (batch A) and in April 2016 (batch B). Seedlings in batch A overwintered outdoors under snow. Thus, the plant material consisted of 12- and 3-month-old seedlings when the experiment started in July 2016. The seedlings were cultivated at Nässja Tree Nursery $\left(60^{\circ} 15^{\prime} \mathrm{N}, 16^{\circ} 50^{\prime} \mathrm{E}\right.$; Bergvik Skog Plantor AB) with their normal water and nutrient schedule. All seedlings of each batch were treated the same in regards to watering and nutrient supply. During the experiment the seedlings were kept outdoors.

The two batches (A and B) were treated with the same experimental plan, except that the timing of LN treatment differed (see below). Before the start of the experiment seedlings were replaced with seedlings from other containers of the same batch if the original seedlings were too small or too large, too bushy or had brown top shoots, or when either no or more than one seedling was growing in the same cavity in a container. In total, 49 containers of each batch were prepared for the experiments.

\section{Treatments}

Six treatments, combining spraying with methyl jasmonate (MeJA) at different concentrations and long night (LN) treatments, were included in the study (Table 1). The seedlings treated with MeJA were also exposed to an LN treatment, although this treatment was delayed until later in the autumn when it no longer affected plant growth but still would

Table 1 Overview of treatments (MeJA= methyl jasmonate; $\mathrm{LN}=$ long night)

\begin{tabular}{llll}
\hline Treatment name & MeJA treatment & LN treatment & Notes \\
\hline No LN & $0 \mathrm{mM}$ & None & $\begin{array}{c}\text { Applied to four containers; } \\
\text { only measured from start } \\
\text { of delayed LN } \\
\text { (10 seedlings/container) }\end{array}$ \\
RLN & None & Regular LN & $\begin{array}{c}\text { Each treatment was applied } \\
\text { to nine containers; }\end{array}$ \\
Control & $0 \mathrm{mM}$ & Delayed LN & seven containers per treat- \\
$5 \mathrm{mM}$ MeJA & $5 \mathrm{mM}$ & Delayed LN & Delayed LN \\
$10 \mathrm{mM} \mathrm{MeJA}$ & $10 \mathrm{mM}$ & Delayed LN & seedlings/container $)$ \\
$15 \mathrm{mM} \mathrm{MeJA}$ & $15 \mathrm{mM}$ & None & 45 seedlings for freezing test \\
$10 \mathrm{mM} \mathrm{MeJA+no} \mathrm{LN}$ & $10 \mathrm{mM}$ & &
\end{tabular}

Each container contained 121 seedlings 
affect dormancy induction and freezing tolerance. From an applied point of view, delaying the LN treatment for some seedlings would be advantageous for forest tree nurseries, as the main cost of LN treatments is related to building and maintaining enough specialized plant beds to treat a large proportion of the seedlings at the same time.

The seedlings were treated as follows.

No LN: seedlings were sprayed with water (with $2.5 \%$ ethanol) following the same schedule as the MeJA treatments. They were not subjected to regular or delayed LN. No LN was included to provide a base line for how the seedlings develop under natural conditions without either LN or MeJA treatments.

RLN: seedlings were exposed to a regular LN (RLN) treatment in accordance with general routines at the nursery. This group represented the conditions under which the seedlings would normally be grown.

Control: seedlings were sprayed with water (with $2.5 \%$ ethanol) following the same schedule as the MeJA treatments. They were not exposed to RLN treatments but were subjected to delayed LN along with the MeJA-treated seedlings. This group provided a direct comparison with the MeJA-treated seedlings.

MeJA: three different concentrations of MeJA, $5 \mathrm{mM}, 10 \mathrm{mM}$ and $15 \mathrm{mM}$, were used to treat seedlings without exposure to RLN. These seedlings were later subjected to delayed LN (excluding 45 seedlings of the $10 \mathrm{mM}$ treatment used for testing freezing tolerance). These three treatment groups were assessed for the effects of different concentrations of MeJA. Treatments with MeJA were timed to coincide with the onset of the RLN treatment (the day before or after the first LN).

\section{MeJA treatment}

All MeJA-treated seedlings were sprayed on three occasions, each 1 week apart. The control $(0 \mathrm{mM})$ and MeJA solutions $(5 \mathrm{mM}, 10 \mathrm{mM}$ and $15 \mathrm{mM})$ were prepared directly before use. Methyl jasmonate (Sigma-Aldrich, Stockholm, Sweden, Ref. \#392707; 95\%) was first dissolved in ethanol and then diluted with deionized water to a $2.5 \%$ ethanol concentration. The liquid was shaken vigorously directly after mixing to obtain a milky emulsion.

MeJA treatments were carried out indoors using pressure sprays (Fri-Sprutan X control; Jape Products AB, Hässleholm, Sweden) calibrated to 2.5 bar. Each concentration had its own pressure spray. Treatments always started with the lowest concentration and were then increased, to prevent confounding effects of previous treatments. The pressure sprays were shaken and the pressure restored by pumping when necessary. After spraying, the seedlings were left standing indoors for $30 \mathrm{~min}$ before being carefully moved outdoors and left standing in separated treatment groups for several hours until they were dry. The containers then were placed randomly back into the outdoor holding area.

Based on an average spraying time of $7.5 \mathrm{~s} /$ container at a rate of $8.26 \pm 0.09 \mathrm{~g}$ liquid/s, each container was sprayed with $61.94 \pm 0.66 \mathrm{~g}$ liquid. The actual amount of liquid reaching the seedlings was measured by repeatedly weighing the containers after spraying for 1-1.5 min. Part of the liquid was lost because it was sprayed onto the floor next to the containers in an effort to reach seedlings in the corners. On average each seedling was sprayed with $0.27 \pm 0.02 \mathrm{~g}$ liquid/treatment. It should be noted, however, that these amounts include not only the liquid on above-ground parts of the seedlings but also on the soil and the container itself. 


\section{Long night treatment}

The LN treatment of the seedlings was carried out according to the nursery's guidelines, and it was done between 19:00 and 8:00. The number of nights that the plant beds were covered differed between the two batches. The nursery staff determined when to end the LN treatment based on timings during the summer and practical considerations (e.g. other seedlings that needed LN). The different durations were thus representative of the usual nursery routines. Seedlings from batch A underwent LN for about 4.5 weeks starting on 29 July 2016, and batch B for 3 weeks starting on 27 July 2016. MeJA-treated seedlings were subjected to a delayed LN treatment for 4.5 weeks starting on 9 September 2016.

\section{Measurements}

Before the first measurement, 10 seedlings in seven containers for each treatment (four containers for No LN) were randomly selected and marked with a small tag in the soil. These seedlings were measured repeatedly throughout the experiment. Height and lower stem diameter (about $0.5 \mathrm{~cm}$ above the soil) were measured once a week from the start of the experiment (beginning of July) until growth had leveled off (mid-September), and thereafter at 2-week intervals until mid-October. The height and diameter of the seedlings were equal between the different treatments within each seedling batch (A and B) at the start of the experiment ( $p>0.05$, Kruskal-Wallis rank sum test, R, version 3.1.1; The $\mathrm{R}$ Foundation for Statistical Computing, Austria). The final height and final diameter of the seedlings were defined as the size they had attained at the last measurement before winter storage. Before winter storage, dead and damaged seedlings were counted. Causes for dead and damaged seedlings were separated in MeJA-caused and "other". Damages were visually assessed and those fitting to characteristic MeJA damages (dead top shoot) were counted as such.

The height growth and diameter growth per day were calculated based on the measured diameter and height of the seedlings, which were taken approximately 1, 2 and 3 weeks after the first MeJA treatment (Table 2). The measurements were estimated to coincide with the expected main effects of MeJA on seedling growth.

\section{Assessment of freezing tolerance and seedling storability}

The development of freezing tolerance in seedlings from batch B was followed in autumn 2016 by performing freezing tests on three occasions, 26 September, 10 October and 10 November. Freezing tolerance tests were not performed with batch A. The development of the batches at this point was very similar, but still seedling age might have influenced the tolerance to freezing. In September and October test temperatures were $-10{ }^{\circ} \mathrm{C}$ and $-25^{\circ} \mathrm{C}$, and in November only $-25^{\circ} \mathrm{C}$. In September freezing was performed on seedlings that had been exposed to RLN, Control, and $10 \mathrm{mM}$ MeJA with and without delayed LN treatments. Forty-five of the $10 \mathrm{mM}$ MeJA seedlings were not exposed to a delayed LN to assess the effects on frost tolerance. In October and November, treatments RLN, Control and 5, 10 and $15 \mathrm{mM}$ MeJA were included in the freezing test.

Freezing tolerance of the seedlings was determined by using a method based on the fact that if cell membrane semi-permeability is disrupted by freezing, the damage can be estimated by measuring the electrolyte leakage (EL) from shoots or other parts of the seedlings (Aronsson and Eliasson 1970; Dexter et al. 1932; L'Hirondelle et al. 2006). Freezing 
Table 2 Assessed variables

\begin{tabular}{ll}
\hline Assessed variable & Based on \\
\hline End height & $\begin{array}{l}\text { Final height before winter storage } \\
\text { Height development 1, 2 and 3 weeks after first methyl jasmonate } \\
\text { Height growth rate }\end{array}$ \\
$\begin{array}{ll}\text { Final diameter before winter storage } \\
\text { Diameter growth rate }\end{array}$ & Diameter development 1, 2 and 3 weeks after first MeJA treatment \\
Needle dry weight & Dry weight \\
Root dry weight & Dry weight \\
Root/shoot weight ratio & Dry weight \\
Needle/stem + branch weight ratio & Dry weight \\
Total root length & Scanning image \\
Average root diameter & Scanning image \\
Fine root/coarse root length ratio & Scanning image \\
Freezing tolerance & Controlled artificial freezing tests \\
Death rate & Proportion of dead seedlings before winter storage \\
Damage rate & Proportion of damaged seedlings before winter storage \\
\hline
\end{tabular}

shoots to $-10{ }^{\circ} \mathrm{C}$ provides an estimate of how seedlings will cope with autumn frosts, while the outcome of the lower exposure to $-25{ }^{\circ} \mathrm{C}$ determines whether the seedlings are ready for frozen storage or not. The storability test includes measuring the shoot electrolyte leakage (SEL \%) after exposure to $-25^{\circ} \mathrm{C}$ and the SEL (\%) from unfrozen shoots. For safe long-term frozen storage, the difference between SEL after freezing and the leakage of unfrozen controls, $\mathrm{SEL}_{\text {diff-25, }}$, should be $\leq 4$ (Brønnum 2005; Lindström and Håkansson 1996; Lindström et al. 2014).

For each treatment included in the freezing tests, randomly selected shoots of 15 seedlings in five replicates were frozen to the target temperatures in a programmable freezer. The upper $2 \mathrm{~cm}$ of the apical shoot of the seedlings were cut off, cleaned in deionized water and put into plastic bottles (each bottle represented one replicate and containing three shoots $)$ and then slowly frozen $\left(2.5^{\circ} \mathrm{C} / \mathrm{h}\right)$ to the target temperatures of $-10{ }^{\circ} \mathrm{C}$ or $-25^{\circ} \mathrm{C}$. The target temperatures were maintained for $1 \mathrm{~h}$. The samples were then slowly thawed $\left(2.5^{\circ} \mathrm{C} / \mathrm{h}\right)$ to $+5^{\circ} \mathrm{C}$. After thawing, $40 \mathrm{ml}$ of deionized water were added to each bottle and the bottles were sealed and shaken for $24 \mathrm{~h}$ in darkness at a temperature of $+20{ }^{\circ} \mathrm{C}$. The electrical conductivity after freezing $\left(\mathrm{EC}_{\text {frozen }}\right)$ to $-10{ }^{\circ} \mathrm{C}$ and $-25{ }^{\circ} \mathrm{C}$ was measured using a conductivity meter (Model Hach SensIon 5) with built-in temperature compensation. The samples were then autoclaved for $10 \mathrm{~min}$ at 1.2 bars pressure and cooled at room temperature. The electrical conductivity was measured again $\left(\mathrm{EC}_{\text {boiled }}\right)$ and relative SEL (\%) after freezing to the target temperatures $\left(\mathrm{SEL}_{-10}\right.$ and $\left.\mathrm{SEL}_{-25}\right)$ was calculated as:

$$
\left(\frac{E C_{\text {frozen }}}{E C_{\text {boiled }}}\right) \times 100
$$

In parallel with the freezing of shoots, samples were prepared (15 shoots in five replicates) to determine the natural leakage from shoots using the same technique as for the frozen samples. The natural leakage was calculated as:

$$
\left(\frac{E C_{\text {control }}}{E C_{\text {boiled }}}\right) \times 100
$$


As the SEL after freezing (Eq. 1) also contains some natural leakage (Eq. 2), the natural leakage was subtracted in order to isolate the effect of freezing to $-10{ }^{\circ} \mathrm{C}\left(\mathrm{SEL}_{\mathrm{diff}-10}\right)$ and $-25^{\circ} \mathrm{C}\left(\mathrm{SEL}_{\mathrm{diff}-25}\right)$.

When the seedlings had reached the target level of being storable $\left(\mathrm{SEL}_{\mathrm{diff}-25} \leq 4\right)$, they were packed into cardboard boxes and stored in a freezer at $-4{ }^{\circ} \mathrm{C}$ in accordance with nursery standards for spring plantation.

\section{Resource allocation}

After winter storage the seedlings were thawed before analyzing whether MeJA treatments had affected the resource allocation between above- and below-ground plant parts. As it was not possible to keep track of the seedlings' affiliation to containers during winter storage, the seedlings used for the resource allocation analyses were randomly selected from the entire material. Final height and final diameter of 15 seedlings each from treatments RLN, Control and $10 \mathrm{mM}$ MeJA were measured on seedlings from batch B. Below-ground parts were removed from above-ground parts. The above-ground parts were separated into needles and woody parts. Woody parts were cut into $1 \mathrm{~cm}$ long pieces. All parts were dried separately in open paper bags for $72 \mathrm{~h}$ at $65^{\circ} \mathrm{C}$ (TS 8430; Termaks, Norway).

The below-ground parts were carefully washed with water to separate the roots from the soil. The roots were stored in $10 \%$ ethanol for a maximum of 1 week. The roots were cut when necessary, scanned (settings 24-bit color, 400 dpi; EPSON Perfection 4990; Seiko Epson Corporation, Japan) and analyzed (WinRHIZO Pro 2007a; Regent Instruments Inc., Canada). The following variables per plant were assessed: total root length, average root diameter, and ratio of fine root length to coarse root length (diameter of fine roots $<0.2 \mathrm{~mm}$ ). After scanning, the roots were transferred into paper bags and dried for $72 \mathrm{~h}$ at $65{ }^{\circ} \mathrm{C}$. After drying the roots were removed from the oven and left at room temperature to cool before weighing the different parts of the seedlings (PE 360; Mettler, Switzerland).

The ratio of root dry weight to shoot dry weight, and the ratio of needle dry weight to stem plus branches dry weight, were calculated from the measured dry weight values of the different parts of a seedling.

\section{Statistical analysis}

For analyzing the statistical difference in final height, final diameter, height growth per day and diameter growth per day, the average was calculated for the contents of each container, i.e. the container was the sample size unit. For analyzing freezing tolerance and resource allocation, the sample size unit was one seedling.

We used Kruskal-Wallis rank sum tests (kruskal.test, stats package; R Software) to test for significant differences in final height, final diameter, height growth per day and diameter growth per day, because most of these were not normally distributed. If the Kruskal-Wallis test was significant, we performed Dunn post-hoc tests with Holm adjustment of the $p$ value (dunn.test package; R Software).

To determine which treatments were freezing tolerant, we performed one-sample Wilcoxon rank sum tests (wilcox.test, stats package; R Software). It has been shown previously that Norway spruce seedlings should be able to tolerate freezing to $-25{ }^{\circ} \mathrm{C}$ to be considered ready for long-term frozen storage. As the cut-off $\mathrm{SEL}_{\mathrm{diff}}$ value for tolerating this temperature is $\leq 4$ (Lindström et al. 2014), the data were tested one sided to be lower than 4 . In 
addition, we performed a Wilcoxon rank sum test to determine whether the delayed LN influenced the frost tolerance of $10 \mathrm{mM}$ MeJA-treated seedlings in September.

The influence of treatments on root/shoot weight ratio, total root length, and fine root/ coarse root length ratio was tested with ANOVAs (aov, stats package; R Software) and a Tukey post-hoc test (TukeyHSD, stats package, R Software). The influence of the treatments on the needle/stem + branch weight ratio as well as on average root diameter was analyzed with Kruskal-Wallis rank sum tests followed by Dunn post-hoc tests.

\section{Results}

\section{Height and height growth}

The final height of the seedlings differed significantly between treatments just before winter storage in both batch A and batch B $(p<0.05$, Kruskal-Wallis rank sum tests; Fig. 1a, Online Resource 1a and 2). The only treatment that reduced the final height significantly compared with RLN was $15 \mathrm{mM}$ MeJA. However, regardless of concentration, all MeJA treatments reduced the final height significantly compared with Control and No LN treatments.

Approximately 1 week after the first MeJA treatment, the height growth rate per day for seedlings from batch B was significantly lower for the MeJA-treated than for RLN and Control seedlings ( $p<0.05$, Kruskal-Wallis rank sum tests; Fig. 1b). After being exposed to long night conditions for 2 or 3 weeks, the growth rate of RLN seedlings had been reduced to a level similar to that of the MeJA-treated seedlings, yet Control seedlings continued to have a higher growth rate during these 3 weeks. The growth rate of seedlings from batch A showed a similar pattern as batch B, although it tended to be slower (Online Resource 1b).

\section{Stem diameter, diameter growth and needle dry weight}

The different treatments affected the final diameter of seedlings from batch B in a similar way as the final height (Fig. 1c). RLN seedlings differed significantly only from 15-mM MeJA seedlings ( $p<0.05$, Kruskal-Wallis rank sum tests), but all concentrations of MeJA had significantly reduced final diameters compared with Control seedlings. The results from batch A were generally similar to those obtained from batch B, although with some differences (Online Resource 1c).

The diameter growth rate per day was the same for all treatments 1 week after the first MeJA treatment $(p<0.05$, Kruskal-Wallis rank sum tests; Fig. 1d, Online Resource 1d). Two and 3 weeks after the initiation of MeJA treatments, seedlings treated with $10 \mathrm{mM}$ and $15 \mathrm{mM}$ MeJA had a lower diameter growth rate than RLN and Control seedlings.

Needle dry weight was the same for RLN, Control and 10-mM MeJA seedlings $(p=0.241$, ANOVA; Fig. 2b).

\section{Size of the root system}

The root dry weight was the same for Control and RLN seedlings ( $p=0.99$, ANOVA; Fig. 2a). The root dry weight of 10-mM MeJA seedlings was significantly lower than that 

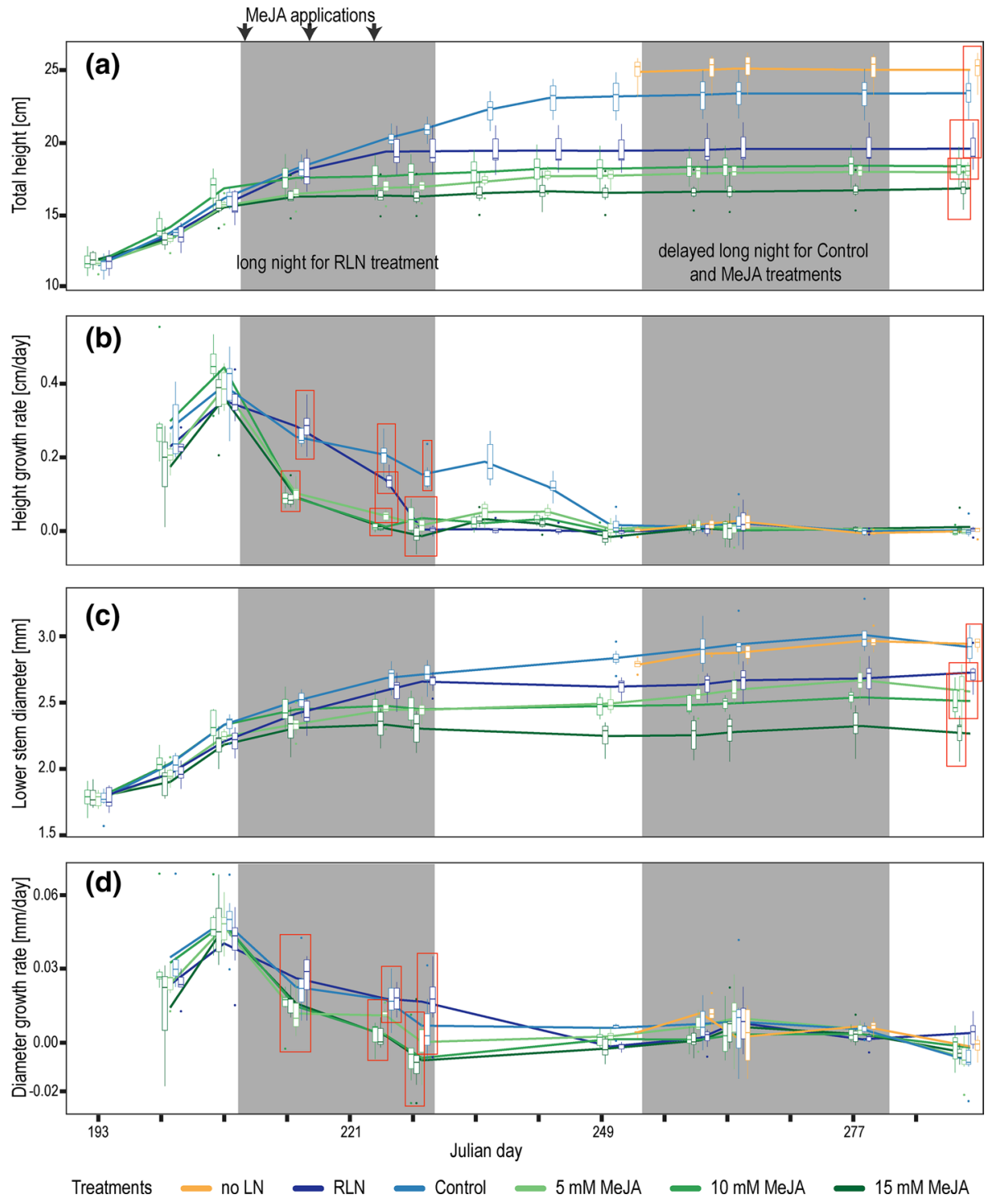

Fig. 1 a Total height $(\mathrm{cm})$, b height growth rate per day $(\mathrm{cm} /$ day), c diameter of lower stem $(\mathrm{mm})$ and $\mathbf{d}$ diameter growth rate of lower stem (mm/day) during the experiment; all data from batch B seedlings. The boxes stretch between the first and third quartiles. The whiskers extend to the highest and lowest values with 1.5 times the inter-quartile range. Data outside this range are plotted as points. Methyl jasmonate (MeJA) treatments are indicated by arrows and long-night (LN) treatments by shaded backgrounds. Squares indicate treatments that were not significantly different; RLN, regular long night 
Fig. 2 Effect of methyl jasmonate (MeJA) treatment on resource allocation as indicated by the variables a dry weight of roots, $\mathbf{b}$ dry weight of needles, c dry weight root/shoot ratio, $\mathbf{d}$ dry weight needle/stem + branch ratio, e total root length, $\mathbf{f}$ diameter of roots and $\mathbf{g}$ fine root/coarse root length ratio for seedlings from batch B. Box properties as in Fig. 1. Treatments with the same letter were not significantly different (a)

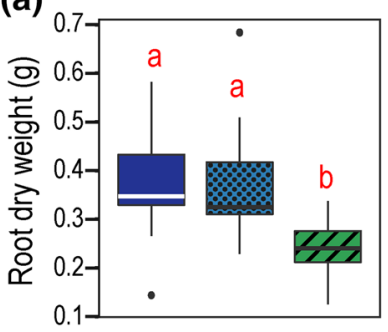

(c)

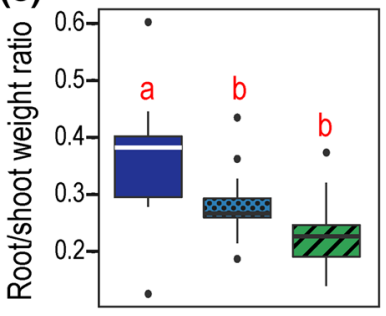

(e)

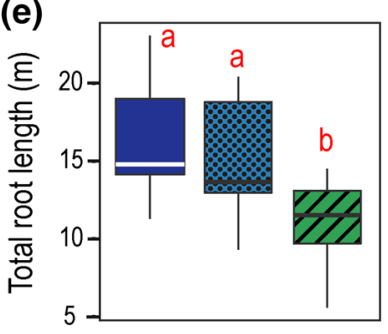

(g)

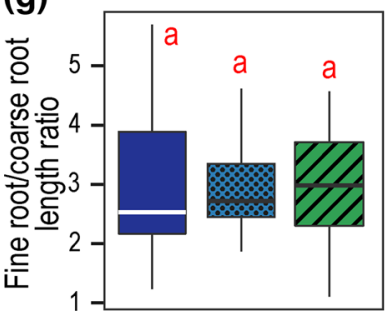

(b)

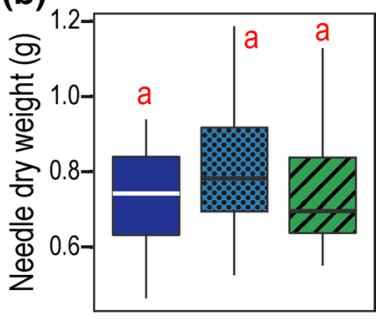

(d)

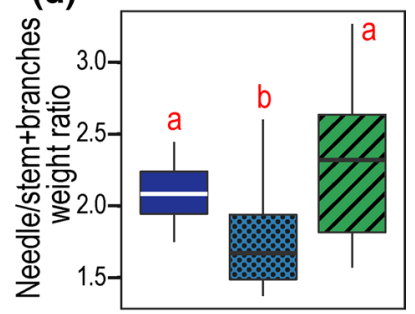

(f)
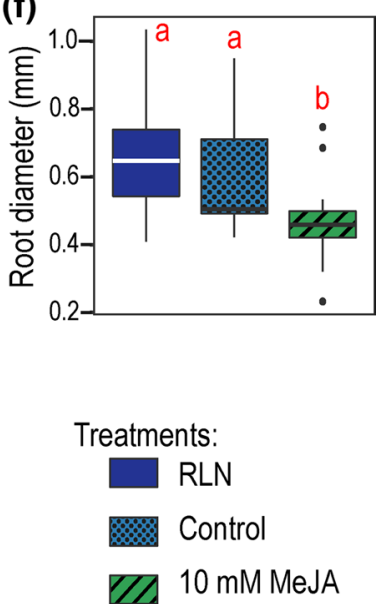

of Control and RLN seedlings ( $p=0.001$ for either, ANOVA; Fig. 2a). The root/shoot weight ratio was higher for RLN seedlings than for Control and 10-mM MeJA seedlings ( $p=0.02$ and $p<0.001$, respectively, ANOVA; Fig. 2c). There was no difference between Control and 10-mM MeJA seedlings $(p=0.17)$. The needle/stem + branch weight ratio was similarly influenced by the RLN and 10-mM MeJA treatments $(p=0.16$, Kruskal Wallis; Fig. 2d); both had higher ratios than the Control seedlings $(p<0.001$ and 0.003 , respectively). The total length and average diameter of the roots were reduced by the $10-\mathrm{mM}$ MeJA treatment compared with the RLN treatment (length: $p<0.001$, ANOVA; Fig. 2e; diameter: $p<0$. 001, Kruskal-Wallis; Fig. 2f) and Control treatment (length: $p=0.003$, diameter: $p=0.01$ ), which did not differ in these response variables (length: $p=0.53$, diameter: $p=0.13$ ). The fine root/coarse root length ratio was not affected by any treatment $(p=0.96$, ANOVA; Fig. 2g). 


\section{Freezing tolerance and seedling storability}

In September, only RLN seedlings showed freezing tolerance, both at $-10{ }^{\circ} \mathrm{C}$ and $-25^{\circ} \mathrm{C}$ ( $p=0.03$, Wilcoxon rank sum tests; Fig. 3a, b; Online Resource 3). The delayed LN treatment positively influenced the freezing tolerance of 10 -mM MeJA-treated plants at $-25{ }^{\circ} \mathrm{C}$ (Fig. 3a, b; Online Resource 3), although complete freezing tolerance was not obtained at the test temperatures $\left(p=0.03\right.$, Wilcoxon). At $-10{ }^{\circ} \mathrm{C}$ there was no difference in freezing tolerance between seedlings with or without delayed $\mathrm{LN}$ treatment ( $p=0.69$, Wilcoxon).

In October, Control and RLN seedlings had developed freezing tolerance at $-10{ }^{\circ} \mathrm{C}$ and $-25{ }^{\circ} \mathrm{C}(p=0.03)$. In November all tested treatments besides $15 \mathrm{mM}$ MeJA had obtained freezing tolerance at $-10{ }^{\circ} \mathrm{C}$ and $-25^{\circ} \mathrm{C}(p=0.03)$.

\section{Vitality of seedlings}

At the end of the experiment, very few seedlings of the MeJA treatments were killed by the treatment but more considerable numbers had treatment-related damage among the $10 \mathrm{mM}$ and, especially, the $15 \mathrm{mM}$ MeJA treatments (Table 3, Online resource 4). In addition seedlings were damaged and killed by other causes, such as drought and physical injury. RLN seedlings and $15 \mathrm{mM}$ MeJA seedlings from batch A showed much higher mortality by other causes than batch B, especially RLN seedlings that were killed by heat/drought (Online resource 4).
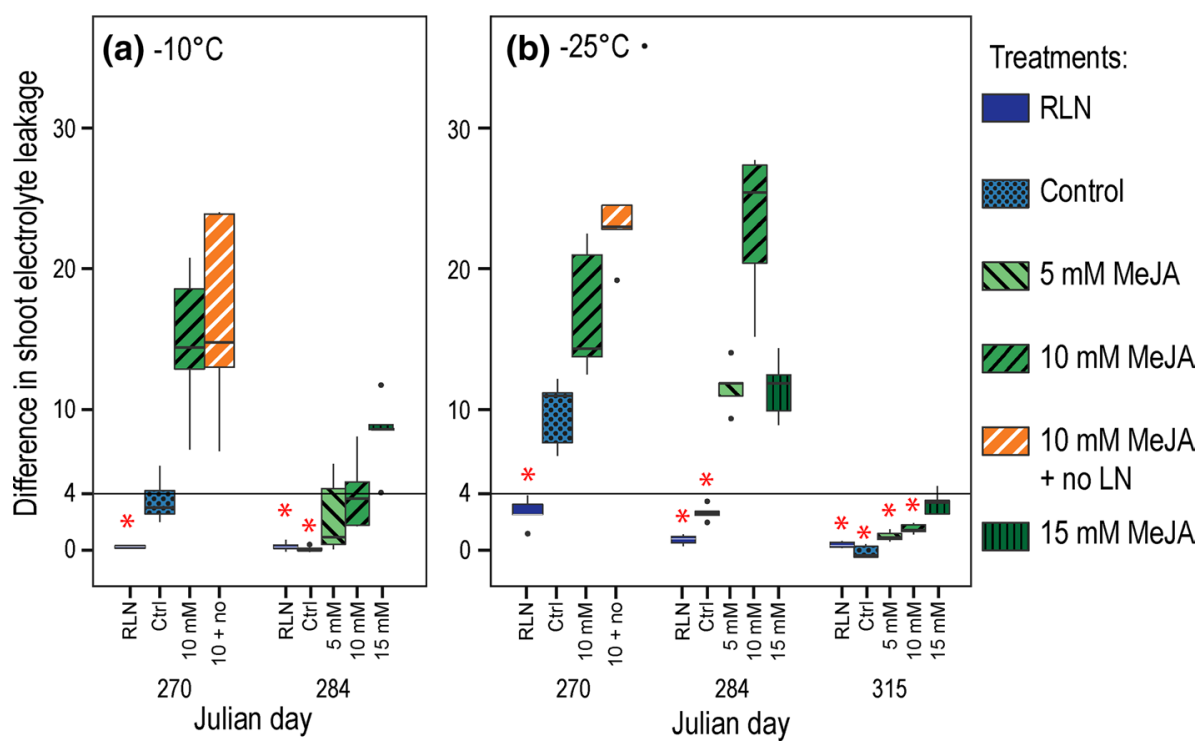

Fig. 3 Freezing tolerance based on differences in shoot electrolyte leakage between frozen and unfrozen seedlings at $\mathbf{a}-10{ }^{\circ} \mathrm{C}$ and $\mathbf{b}-25^{\circ} \mathrm{C}$ of seedlings from batch $\mathrm{B}$ at different time points. Box properties as in Fig. 1. A one-sided significant difference below a cut-off value of 4 is indicated by an asterisk $(*)$ 
Table 3 Number of dead seedlings killed by MeJA treatments or by other causes, and the number of damaged seedlings by MeJA or other causes until winter storage; all data from batch B seedlings ( $\mathrm{n}$ per treatment $=1089$ )

\begin{tabular}{llllll}
\hline \multirow{2}{*}{ Treatment } & \multicolumn{2}{l}{ Killed by } & & \multicolumn{2}{c}{ Damaged by } \\
\cline { 2 - 3 } \cline { 5 - 6 } & MeJA & Other causes & & MeJA & Other causes \\
\hline RLN & - & 9 & & - & 43 \\
Control & - & 0 & & 35 \\
5 mM MeJA & 2 & 3 & & 45 \\
$10 \mathrm{mM} \mathrm{MeJA}$ & 0 & 0 & & 49 & 38 \\
$15 \mathrm{mM}$ MeJA & 9 & 3 & & 257 & 19 \\
\hline
\end{tabular}

\section{Discussion}

\section{Above-ground growth}

As expected, seedlings treated with MeJA or RLN showed reduced apical shoot growth compared with Control seedlings. Furthermore, higher concentrations of MeJA resulted in a larger reduction of growth, as has been seen in previous studies (Gould et al. 2009; Heijari et al. 2005). A novel result of practical interest is that moderate concentrations of MeJA (5-10 $\mathrm{mM}$ ) resulted in similar final heights as the RLN treatment. With the highest concentration of MeJA (15 mM), the final height was even lower than with RLN.

The final diameter reacted similarly to the final height to the treatments with MeJA, but to a much smaller extent. The $15-\mathrm{mM}$ and $10-\mathrm{mM}$ MeJA treatments significantly reduced the final diameter compared with the Control treatment. Previous studies have also shown reduced diameters after MeJA treatment of conifer seedlings (Heijari et al. 2005; Moreira et al. 2012; Sampedro et al. 2011). In late autumn, all MeJA-treated seedlings had either similar or smaller final diameters compared with RLN seedlings. However, the final diameter of RLN seedlings did not differ from the diameter of Control seedlings. Some previous studies support this finding (Colombo et al. 2003), whereas others either report larger diameters (Kohmann and Johnsen 2007) or smaller diameters for LN-treated seedlings compared with control seedlings (Fløistad and Granhus 2013; Konttinen et al. 2007).

As well as the properties of seedlings at the end of the growing season, the speed of the response to different treatments is an important factor to consider, as this can influence their practical use in forest tree nurseries. At the first measurement after application (7 days), MeJA-treated seedlings already showed a reduced height growth rate compared with Control seedlings. This reaction to MeJA treatment was remarkably quick compared with the reaction to the RLN treatment, which did not result in any significant reduction of height growth rate for the first 2 weeks of treatment. Similarly, Wallin et al. (2017) found no significant growth reductions during the first week when testing different periods of $\operatorname{RLN}$ treatment $(0,7,14,21$, and 28 days) on spruce. At the end of the second week, however, apical shoot growth was significantly lower for RLN seedlings, and at the end of the third week growth had almost ceased completely. The study by Wallin et al. (2017) also indicated that 7 days of RLN treatment could be enough to stop the growth of Norway spruce but too short to start effectively the process of activating the genes related to dormancy and freezing tolerance development. In conclusion, the height development of seedlings can be controlled at least as effective with MeJA as with RLN.

When Norway spruce seedlings have reached the target height, MeJA application could stop growth quickly. When using $\mathrm{LN}$, it is important to consider the natural critical night 
length of a provenance (the night length that promotes bud set of a provenance). Shorter durations of LN treatment as well as premature termination of LN treatment, when the natural night is still short, may result in a second bud flush, causing deteriorated seedling quality (Kohmann and Johnsen 2007; Fløistad and Granhus 2013; Luoranen and Rikala 2015). The use of MeJA applications during the summer could potentially ensure that seedlings will not resume apical growth after LN treatment has been completed. However, after an initial decrease in height growth, Gould et al. (2008) observed a subsequent increase in height growth rate of MeJA-treated Pinus radiata after 2 weeks. This might be because their seedlings were only treated once with MeJA compared with three times in the present study. In our study, seedlings retained a reduced growth rate for at least 3 weeks, which might have been because of a build-up effect caused by the repeated treatments with MeJA. However, a previous experiment has shown that even after repeated MeJA treatments the initial loss of growth will be compensated although it takes longer time, i.e. approximately two field seasons (Zas et al. 2014). The subset of seedlings from this study that was later planted in a field experiment generally established and grew satisfactory, including the higher MeJA treatments (unpublished data).

The diameter growth rate results were not as clear as the height growth results and we could only measure an effect of MeJA at some time points. As our experiments were started in late July, this may have been after the main period of diameter growth (Kohmann and Johnsen 2007). Nevertheless there was a cumulative reduction, with the final diameter of MeJA seedlings being reduced compared with the Control seedlings.

Although apical shoot growth was reduced by MeJA treatment, needle growth appeared not to have been negatively affected by MeJA or RLN treatments, as dry weight was not affected. Moreira et al. (2012) found that MeJA treatments influence the biomass of adult, but not juvenile, needles negatively. In the present study, needle dry weights were similar among treatments, while the needle/stem + branch weight ratio was higher for RLN and MeJA seedlings compared with Control seedlings, which indicates that needles on RLNand MeJA-treated seedlings are either larger/longer or tighter than on Control seedlings. Most likely, the needles stand closer together, as has been observed on MeJA-treated Pinus pinaster seedlings (Moreira et al. 2012).

\section{Roots}

Compared with RLN and Control seedlings, 10-mM MeJA seedlings had in addition to the reduced shoot growth (see above), also reduced root length and diameter growth. As the root/shoot weight ratio was reduced in the 10-mM MeJA seedlings, this means that the roots were proportionally more reduced in growth than the above-ground parts of the seedlings. However, as the root/shoot weight ratio of 10-mM MeJA seedlings and Control seedlings were similar, the reduced proportional growth was not the result of MeJA treatment, but either the lack of an RLN or delayed LN treatment. This result is in contrast to previously published results on Pinus pinaster seedlings, which had an increased root to shoot ratio after treatment with MeJA (Moreira et al. 2012). RLN did not influence root dry weight, as also shown by Fløistad and Granhus (2013), root length or average root diameter. MeJA, on the other hand, influenced root dry weight, length and average diameter negatively. Previous studies have reported similar negative effects of MeJA (Heijari et al. 2005; Vivas et al. 2012) but also opposite results (Moreira et al. 2012). Moreira et al. (2012) found that there was an increase in fine roots, whereas coarse roots were reduced, which we did not find in the present study. To clarify these contradicting results, a study 
looking specifically at the influence of MeJA on the root development of seedlings of different species would be useful.

Despite the negative effect of MeJA treatment on root development, there was no problem with the establishment of seedlings when they were planted on clear-cuts in the following summer. Per treatment, including Control and RLN, only one to three seedlings of each batch of 450 planted seedlings died because of drought in the year of planting (unpublished data).

\section{Freezing tolerance and seedling storability}

This study indicates that MeJA treatment of Norway spruce seedlings results in a delayed dormancy and development of tolerance to freezing. The MeJA treatment may have delayed the activation of the different genes responsible for the start of dormancy induction and the later development of freezing tolerance (Wallin et al. 2017). A delayed development of freezing tolerance will result in seedlings that are ready for safe frozen storage at a later date (Lindström et al. 2014). This could cause practical problems for a nursery and emphasizes the importance of using reliable tests for storability before seedlings are put into storage (Stattin et al. 2012). There is a need for further studies on how the timing of MeJA treatments affects the outcome of apical growth cessation and how the application can be used to minimize problems in obtaining sufficient freezing tolerance for either autumn planting or frozen storage. A first step could be to study how the genes related to dormancy and freezing tolerance (Wallin 2018; Wallin et al. 2017) are affected by MeJA treatment.

\section{Vitality effects of treatment}

High concentrations of MeJA can cause reduced photosynthetic rates and phytotoxic symptoms such as needle browning and apical resinosis (Gould et al. 2009; Heijari et al. 2005; Vivas et al. 2012). An increased mortality rate of seedlings treated with high MeJA concentrations was observed in the present study and by Heijari et al. (2005). At the lower concentrations of MeJA used in this study, mortality rates were, however, low (i.e. $<1 \%$ for $5 \mathrm{mM}$ and $<5 \%$ for $10 \mathrm{mM}$ ).

\section{Conclusion}

Forest nurseries need tools that can stop the growth of conifer seedlings once they have reached their optimal size. In this study we show that MeJA appears to be a promising candidate, as it can terminate apical growth with the same or better efficiency as LN treatments. However, other positive effects of LN treatments (freezing tolerance) are not achieved and may require different timings of MeJA/delayed LN treatments, e.g. delayed LN treatment in late summer may still provide sufficient freezing tolerance. Thus, MeJA does not provide a complete solution for eliminating LN treatments, but the addition of a MeJA treatment can make the use of LN treatments in nurseries more flexible. If the period during which LN treatments can be applied can be extended by using MeJA, LN equipment can be used more efficiently. MeJA treatments seem to have more positive practical effects (reduced height) than negative effects (reduced frost tolerance) and could, 
with further technical development, become an option for forest tree nurseries instead of investing in additional LN equipment.

Acknowledgements Open access funding provided by Swedish University of Agricultural Sciences. We thank all the staff at Nässja Tree Nursery for their practical help and welcoming atmosphere, Marianne Vemhäll and Elisabeth Wallin for conducting the freezing tests, Claes Hellqvist for keeping track of plants before storage, Claudia von Brömssen and Ulf Olsson for help with statistics, Stefanie Hoeber and Dimitrije Markovic for introducing us to root analysis, and our laboratory assistants for practical help. This study was funded by the Swedish Research Council FORMAS (Grant No. 942-2015-70 to NB), and was part of the Swedish Hylobius Research Program financed by the Swedish forestry sector (Grant to GN).

Open Access This article is distributed under the terms of the Creative Commons Attribution 4.0 International License (http://creativecommons.org/licenses/by/4.0/), which permits unrestricted use, distribution, and reproduction in any medium, provided you give appropriate credit to the original author(s) and the source, provide a link to the Creative Commons license, and indicate if changes were made.

\section{References}

Aronsson A, Eliasson L (1970) Frost hardiness in Scots pine (Pinus silvestris L.) I. Conditions for test on hardy plant tissues and for evaluation of injuries by conductivity measurements. Stud For Suec 77:1-30

Berglund T, Lindström A, Aghelpasand H, Stattin E, Ohlsson AB (2016) Protection of spruce seedlings against pine weevil attacks by treatment of seeds or seedlings with nicotinamide, nicotinic acid and jasmonic acid. Forestry 89:127-135. https://doi.org/10.1093/forestry/cpv040

Brønnum P (2005) Assessment of seedling storability of Quercus robur and Pinus sylvestris. Scand J Forest Res 20:26-35. https://doi.org/10.1080/02827580410019526

Colombo SJ, Menzies MI, O'Reilly C (2001) Influence of nursery cultural practices on cold hardiness of coniferous forest tree seedlings. In: Bigras FJ, Colombo SJ (eds) Conifer cold hardiness. Springer, Dordrecht, pp 223-252. https://doi.org/10.1007/978-94-015-9650-3_9

Colombo SJ, Glerum C, Webb DP (2003) Daylength, temperature and fertilization effects on desiccation resistance, cold hardiness and root growth potential of Picea mariana seedlings. Ann For Sci 60:307317. https://doi.org/10.1051/forest:2003022

Dexter ST, Tottingham WE, Graber LF (1932) Investigations of the hardiness of plants by measurement of electrical conductivity. Plant Physiol 7:63-78. https://doi.org/10.1104/pp.7.1.63

Fedderwitz F, Nordlander G, Ninkovic V, Björklund N (2016) Effects of jasmonate-induced resistance in conifer plants on the feeding behaviour of a bark-chewing insect, Hylobius abietis. J Pest Sci 89:97105. https://doi.org/10.1007/s10340-015-0684-9

Fløistad I, Granhus A (2013) Timing and duration of short-day treatment influence morphology and second bud flush in Picea abies seedlings. Silva Fennica. https://doi.org/10.14214/sf.1009

Gould N, Reglinski T, Spiers M, Taylor JT (2008) Physiological trade-offs associated with methyl jasmonate-induced resistance in Pinus radiata. Can J For Res 38:677-684. https://doi.org/10.1139/ x07-193

Gould N, Reglinski T, Northcott GL, Spiers M, Taylor JT (2009) Physiological and biochemical responses in Pinus radiata seedlings associated with methyl jasmonate-induced resistance to Diplodia pinea. Physiol Mol Plant Pathol 74:121-128. https://doi.org/10.1016/j.pmpp.2009.10.002

Gu T, Zhang C, Chen C, Li H, Huang K, Tian S, Zhao X, Hao D (2018) Effects of exogenous methyl jasmonate-induced resistance in Populus $x$ euramericana 'Nanlin895' on the performance and metabolic enzyme activities of Clostera anachoreta. Arthropod-Plant Interact 12:247-255. https://doi. org/10.1007/s11829-017-9564-y

Heijari J, Nerg AM, Kainulainen P, Viiri H, Vuorinen M, Holopainen JK (2005) Application of methyl jasmonate reduces growth but increases chemical defence and resistance against Hylobius abietis in Scots pine seedlings. Entomol Exp Appl 115:117-124. https://doi.org/10.111 1/j.1570-7458.2005.00263.x

Jacobs DF, Davis AS, Wilson BC, Dumroese RK, Goodman RC, Salifu KF (2008) Short-day treatment alters Douglas-fir seedling dehardening and transplant root proliferation at varying rhizosphere temperatures. Can J For Res 38:1526-1535. https://doi.org/10.1139/X08-020 
Jiang D, Yan S (2018) MeJA is more effective than JA in inducing defense responses in Larix olgensis. Arthropod-Plant Interact 12:49-56. https://doi.org/10.1007/s11829-017-9551-3

Kohmann K, Johnsen O (2007) Effects of early long-night treatment on diameter and height growth, second flush and frost tolerance in two-year-old Picea abies container seedlings. Scand J Forest Res 22:375-383. https://doi.org/10.1080/02827580701520486

Konttinen K, Luoranen J, Rikala R (2007) Growth and frost hardening of Picea abies seedlings after various night length treatments. Balt For 13:140-148

L'Hirondelle SJ, Simpson DG, Binder WD (2006) Overwinter storability of conifer planting stock: operational testing of fall frost hardiness. New For 32:307. https://doi.org/10.1007/s11056-006-9005-8

Lindström A, Håkansson L (1996) The EC-method-a way to assess storability of forest tree seedlings (in Swedish). Swedish University of Agricultural Sciences, Department of Forest Yield Research, Report, p 95

Lindström A, Stattin E, Gräns D, Wallin E (2014) Storability measures of Norway spruce and Scots pine seedlings and assessment of post-storage vitality by measuring shoot electrolyte leakage. Scand J For Res 29:717-724. https://doi.org/10.1080/02827581.2014.977340

López-Goldar X, Villari C, Bonello P, Borg-Karlson AK, Grivet D, Zas R, Sampedro L (2018) Inducibility of plant secondary metabolites in the stem predicts genetic variation in resistance against a key insect herbivore in maritime pine. Front Plant Sci 9:1651. https://doi.org/10.3389/fpls.2018.01651

Lundborg L, Fedderwitz F, Björklund N, Nordlander G, Borg-Karlson A-K (2016a) Induced defenses change the chemical composition of pine seedlings and influence meal properties of the pine weevil Hylobius abietis. Phytochemistry 130:99-105. https://doi.org/10.1016/j.phytochem.2016.06.002

Lundborg L, Nordlander G, Björklund N, Nordenhem H, Borg-Karlson AK (2016b) Methyl jasmonateinduced monoterpenes in Scots pine and Norway spruce tissues affect pine weevil orientation. J Chem Ecol 42:1237-1246. https://doi.org/10.1007/s10886-016-0790-z

Luoranen J, Rikala R (2015) Post-planting effects of early-season short-day treatment and summer planting on Norway spruce seedlings. Silva Fennica. https://doi.org/10.14214/sf.1300

Luoranen J, Saksa T, Lappi J (2018) Seedling, planting site and weather factors affecting the success of autumn plantings in Norway spruce and Scots pine seedlings. For Ecol Manag 419-420:79-90. https://doi.org/10.1016/j.foreco.2018.03.040

Moreira X, Zas R, Sampedro L (2012) Genetic variation and phenotypic plasticity of nutrient re-allocation and increased fine root production as putative tolerance mechanisms inducible by methyl jasmonate in pine trees. J Ecol 100:810-820. https://doi.org/10.1111/j.1365-2745.2011.01938.X

Sampedro L, Moreira X, Zas R (2011) Costs of constitutive and herbivore-induced chemical defences in pine trees emerge only under low nutrient availability. J Ecol. https://doi.org/10.111 1/j.1365-2745.2011.01814.x

Stattin E, Verhoef N, Balk P, van Wordragen M, Lindström A (2012) Development of a molecular test to determine the vitality status of Norway spruce (Picea abies) seedlings during frozen storage. New For 43:665-678. https://doi.org/10.1007/s11056-012-9320-1

Vivas M, Martín JA, Gil L, Solla A (2012) Evaluating methyl jasmonate for induction of resistance to Fusarium oxysporum, F. circinatum and Ophiostoma novo-ulmi. For Syst 21:289-299. https://doi. org/10.5424/fs/2012212-02172

Wallin E (2018) From growth cessation to bud burst- conifer seedling development in response to nursery culture and environmental stimuli. Dissertation, Swedish University of Agricultural Sciences. Acta Universitatis agriculturae Sueciae 2018:12. https://pub.epsilon.slu.se/15328/

Wallin E, Gräns D, Jacobs DF, Lindström A, Verhoef N (2017) Short-day photoperiods affect expression of genes related to dormancy and freezing tolerance in Norway spruce seedlings. Ann For Sci. https ://doi.org/10.1007/s13595-017-0655-9

Yu X, Zhang W, Zhang Y, Zhang X, Lang D, Zhang X (2018) The roles of methyl jasmonate to stress in plants. Funct Plant Biol (published online). https://doi.org/10.1071/FP18106

Zas R, Björklund N, Nordlander G, Cendán C, Hellqvist C, Sampedro L (2014) Exploiting jasmonateinduced responses for field protection of conifer seedlings against a major forest pest, Hylobius abietis. For Ecol Manag 313:212-223. https://doi.org/10.1016/j.foreco.2013.11.014

Zhao T, Borg-Karlson A-K, Erbilgin N, Krokene P (2011) Host resistance elicited by methyl jasmonate reduces emission of aggregation pheromones by the spruce bark beetle, Ips typographus. Oecologia 167:691-699. https://doi.org/10.1007/s00442-011-2017-x

Publisher's Note Springer Nature remains neutral with regard to jurisdictional claims in published maps and institutional affiliations. 